\title{
La métallurgie du fer dans les Deux-Sèvres et la Vienne
}

\section{Guillaume Saint-Didier}

\section{OpenEdition Journals}

Édition électronique

URL : http://journals.openedition.org/adlfi/3013

ISSN : 2114-0502

Éditeur

Ministère de la culture

Référence électronique

Guillaume Saint-Didier, "La métallurgie du fer dans les Deux-Sèvres et la Vienne », ADLFI. Archéologie de la France - Informations [En ligne], Poitou-Charentes, mis en ligne le 01 mars 2009, consulté le 01 mai 2019. URL : http://journals.openedition.org/adlfi/3013

Ce document a été généré automatiquement le 1 mai 2019.

(c) Ministère de la Culture et de la Communication, CNRS 


\title{
La métallurgie du fer dans les Deux- Sèvres et la Vienne
}

\author{
Guillaume Saint-Didier
}

Identifiant de l'opération archéologique : 204702

Date de l'opération : 2009 (PT)

1 Les prospections archéologiques pédestres menées en 2009 dans les départements des Deux-Sèvres et de la Vienne s'inscrivent dans le cadre de ma thèse préparée à l'université de Poitiers, sous la direction de Nadine Dieudonné-Glad, et débutée à la fin de l'année 2007. Son sujet porte sur la métallurgie du fer chez les Pictons de La Tène finale à la fin de la période romaine. Cette campagne de prospections 2009 est la deuxième de cette thèse.

2 Les prospections réalisées en 2008 ont confirmé le potentiel en sites sidérurgiques anciens (ferriers, minières) de la Vienne et démontré celui des Deux-Sèvres, jusqu'alors inconnu.

La campagne 2009 devait répondre à plusieurs objectifs :

- continuer la vérification au sol de ferriers déjà connus et en découvrir de nouveaux. Mettre en évidence d'autres sites liés au minerai de fer ;

5 - mieux définir les secteurs sidérurgiques reconnus en 2008. Il s'agissait de les délimiter géographiquement et de mettre en évidence plusieurs de leurs caractéristiques grâce à la découverte d'autres sites sidérurgiques ;

6 - vérifier au sol le potentiel de secteurs ayant livré de nombreux toponymes pouvant tirer leur origine d'une activité sidérurgique passée («Ferrière » par exemple);

7 - dater, comme en 2008, un maximum de ferriers prospectés.

8 Au total, pas moins de 73 communes ont été prospectées et ont permis d'enregistrer un ensemble de 133 sites, parmi lesquels 117 sont effectivement à caractère sidérurgique 
(ferriers, minières, sites de minerai de fer). Cent dix-huit de ces sites sont inédits. Cet ensemble de sites a permis de confirmer l'existence des secteurs sidérurgiques définis en 2008 et d'en découvrir de nouveaux; ces secteurs ont pu être mieux caractérisés. Comme en 2008, nombreux sont les ferriers qui ont pu être datés (presque la moitié), ce qui est tout à fait exceptionnel pour ce genre de sites.

9 À terme, l'objectif de ces prospections est de disposer de suffisamment de données pour espérer comprendre le mieux possible l'économie du fer à l'époque romaine sur le territoire de la civitasdes Pictons. Il s'agit donc de tenter de relier les sites d'extraction de minerai aux ateliers de travail du fer. C'est pourquoi, des scories, des fragments de minerai et de parois de fours ont été collectés sur les sites prospectés afin de procéder à des analyses chimiques visant à caractériser la composition de ces éléments.

SAINT-DIDIER Guillaume

INDEX

operation Prospection thématique (PRT)

Index chronologique : Empire romain, La Tène

Thèmes : atelier métallurgique, fer, ferrier, four, scories, sidérurgie, site d'extraction

Index géographique : Poitou-Charentes, Deux-Sèvres (79)

\section{AUTEURS}

GUILLAUME SAINT-DIDIER

DOC 